\title{
Glucocorticoid hormone-induced modulation of gene expression and regulation of T-cell death: role of GITR and GILZ, two dexamethasone-induced genes
}

\author{
C Riccardi ${ }^{*, 1}$, MG Cifone ${ }^{2}$ and G Migliorati ${ }^{1}$ \\ 1 Department of Clinical and Experimental Medicine, University of Perugia, Via \\ del Giochetto, 06100 Perugia, Italy \\ ${ }^{2}$ Department of Experimental Medicine, University of l'Aquila, Via Vetoio 10, \\ Coppito 2, 67100 L'Aquila, Italy \\ * Corresponding author: Carlo Riccardi, MD, PhD, Department of Clinical and \\ Experimental Medicine, Section of Pharmacology, Perugia University Medical \\ School, Via del Giochetto, 06100 Perugia, Italy. Tel: 3975 5853467; \\ Fax: 3975 5853405; E-mail: riccardi@unipg.it
}

Received 29.6.99; revised 30.9.99; accepted 7.10.99 Edited by L Fesus

\begin{abstract}
Regulation of T-cell survival is a physiological process involved in determining the immune response development, and also the expansion of T-cell tumours. Glucocorticoid hormones (GCH) have been implicated as regulators of Tlymphocyte growth and differentiation. In particular, $\mathrm{GCH}$ which by themselves are apoptosis activators and induce Tcell death, can also counteract apoptosis activated by other stimuli, for example antigen-TCR interaction. A number of biochemical events constitute different $\mathrm{GCH}$-activated deathtriggering pathways and transcription activity regulation, either upstream and/or downstream in the pathways, is essential to apoptosis. Similarly, GCH-mediated inhibition of apoptosis also requires gene transcription regulation. In particular, between a number of GCH-induced genes, GITR and GILZ can inhibit apoptosis through interaction with mechanisms involved in T-cell survival regulation including the NF- $k$ B transcription activity and the expression of the Fas/ FasL system. These observations indicate that this $\mathrm{GCH}$ activated dual effect, induction and/or inhibition of T-cell death, requires transcription regulation.
\end{abstract}

Keywords: glucocorticoid hormones; T lymphocytes; gene transcription; apoptosis

Abbreviations: AICD, activation-induced cell death; $\mathrm{Ag}$, antigen; aSMase, acidic sphingomyelinase; CK, cytokines; CREB, CAMP response element binding protein; CTL, cytotoxic T lymphocytes; DEX, dexamethasone; GCH, glucocorticoid hormones; GILZ, glucocorticoid-induced leucin zipper gene; GITR, glucocorticoidinduced TNFR family-related gene; GR, glucocorticoid receptor;
GRE, glucocorticoid response element; HSP70, heat shock protein 70; iNOS, inducible nitric oxide synthase; LIP-1, lipocortin-1; mAbs, monoclonal antibodies; MHC, major histocompatibility complex; $\mathrm{NO}$, nitric oxide; NOS, nitric oxide synthase; PCD, programmed cell death; PGs, prostaglandins; PI-PLC, phosphatidylinositol-specific phospholipase $\mathrm{C} ; \mathrm{PLA} \mathrm{A}_{2}$, phospholipase $\mathrm{A}_{2} ; \mathrm{SEB}$, Staphylococcus enterotoxin B; SP, single positive; TCR, T-cell receptor; TNF/NFGR, tumor necrosis factor/nerve growth factor receptor

\section{Introduction}

Glucocorticoid hormones $(\mathrm{GCH})$ are commonly used as therapeutic agents for many acute and chronic inflammatory and auto-immune diseases, in transplant patients, and in the treatment of leukemias and lymphomas. ${ }^{1-5}$ The therapeutic action of these compounds has largely been attributed to their anti-inflammatory and immunosuppressive efficacy and to their growth arrest and death inducing activity. Most of their effects are due to the interaction wfith cytoplasm glucocorticoid receptors (GR) and modulation of gene transcription by direct GR/DNA interaction or by DNA-binding independent mechanisms which may involve protein to protein interactions. ${ }^{1-3,6,7}$ These effects comprise either up-regulation of expression of some molecules, such as lipocortin-1 (LIP-1) and a number of cytokine receptors, or transcription inhibition of others such as nitric oxide synthase (NOS), tachykinin NK1 receptor, a number of cytokines (NK) and some adhesion molecules. ${ }^{2,8-10}$ An important aspect of the $\mathrm{GCH}$ activity is the interaction with the immune system and in particular the effect directed on T-lymphocytes, whose growth, differentiation and redistribution can be influenced.

\section{The T-cell response: the role of apoptotic selection}

The immune T-cell compartment maintains the capability to respond to a wide variety of antigens $(\mathrm{Ag})$. This capability is also due to the maintaining of living naïve and memory $T$ cells that express different T-cell receptors (TCR). The pool of selfmajor histocompatibility complex (MHC)-restricted TCR $\alpha \beta+\mathrm{T}$ lymphocytes is generated during T-cell development in the thymus by a positive selection process, whereas negative selection through apoptosis, ensures that the immune system is self-tolerant. ${ }^{11}$ Selected cells are exported in the periphery as single positive (SP) lymphocyte, and continuous $\mathrm{MHC}$ recognition is required for the persistence of $\mathrm{CD}^{+}$ (recognition of $\mathrm{MHC} \mathrm{II)} \mathrm{and} \mathrm{CD8+} \mathrm{(recognition} \mathrm{of} \mathrm{MHC} \mathrm{I}$ ) cells. The pool of SP T cells survives in the periphery for life 
and selection becomes active again when an $\mathrm{Ag} / \mathrm{T}$-cell interaction occurs. In particular, some activated $\mathrm{T}$ cells survive (positive selection) the Ag/TCR-interaction, initiate cell cycle progression and proliferation to constitute the immune response, while many others die (negative selection) after activation (activation-induced cell death, AICD). These events are transcription-dependent, contribute to change the repertoire during life and induce the accumulation of memory cells which survive the Ag/TCR interaction. ${ }^{12,13}$

All this process involves the co-ordinated expression of a great number of genes, including those coding for cytokines and their receptors, such as for example IL-2, IFN $\gamma$, TNF $\alpha$ and the Fas/FasL system. ${ }^{14-17} \mathrm{~A}$ number of genes, coding for transcription factors, have also been proposed to be involved in the selection process either to maintain resting $T$ cells surviving, this is the case of LKLF transcription factor, ${ }^{18}$ or contributing as regulators of specific $T$ cell activation and death, such as for example AP-1, NFAT, NF$\kappa \mathrm{B}, \mathrm{P} 53$ and CAMP response element binding proteins (CREB). In addition, other genes including those of the bcl2 and caspases families, contribute to regulate lymphocyte deletion and/or survival. ${ }^{19,20}$ All the above molecules and transcription factors should be expressed in a co-ordinated manner so that an organism maintains the capability to develop an immune response against viral and bacterial antigens, also in adults when thymus atrophy occurs, to return to normal levels of reactivity when the immune response is not longer requested for host defence, and autoimmunity could occur due to an excessive response. Moreover, long-surviving memory cells are maintained after Ag elimination.

Ag-induced apoptosis, a transcription-dependent event, plays an important role in the deletion of 'unwanted' T cells in two phases in the ontogeny of the immune response. ${ }^{21-23}$ First, in the thymus, immunological tolerance to self-antigens can be acquired through negative selection of autoreactive $T$ cells. Second, in the periphery, Ag-stimulation of the TCR/ CD3 complex leads to activation or anergy, and also to apoptosis (programmed cell death, PCD). In particular, it has been reported that the apoptosis of peripheral activated $T$ cells, induced after activation by Ag such as Staphylococcus enterotoxin B (SEB) or immobilised anti-CD3 monoclonal antibodies (mAbs), occurs through a Fas/Fas-L-mediated autocrine suicide. ${ }^{24-26}$

\section{The role of coaccessory molecules in T-cell apoptosis}

Signals, other than $\mathrm{Ag} / \mathrm{TCR}$ interaction, are involved in regulating $\mathrm{T}$-cell death. In particular, coaccessory molecules, including CD4, CD28, CD44, CD2, and cytokines such as IL-2, IL-4 and IL-9, may be involved in regulating $\mathrm{T}$ cell apoptosis. ${ }^{27-33}$

$\mathrm{GCH}$ regulators are also critical regulators of $\mathrm{T}$-cell apoptosis in that they simultaneously activate a cell suicide and an anti-death program that also may contribute to determine susceptibility or resistance of cells. ${ }^{34-37}$ In particular, dexamethasone (DEX)-, a synthetic $\mathrm{GCH}$ specific for GR, induced cell death has been described in hybridoma $\mathrm{T}$ cells as well as in normal $\mathrm{T}$ cells, including thymocytes, peripheral lymphocytes (lymph node and spleen) and allospecific cytotoxic $T$ lymphocytes (CTL). Moreover, mutual exclusion between two apoptosis inducers, namely anti-CD3 mAbs and DEX, has also been described in a T-cell hybridoma and normal $\mathrm{T}$ cells, indicating that $\mathrm{GCH}$ can also counter cell death and contribute to $T$ cell survival. ${ }^{37-40}$ This binary effect, PCD activation and inhibition, is not surprising and it has been reported that $\mathrm{GCH}$ activate the caspases cascade, a central mechanism involved in T-cell apoptosis, and inhibit $\mathrm{NF}-\kappa \mathrm{B}$, a transcription factor complex important in cell survival, but also weaken the activation-induced transcription increase of Fas and FasL, that play an important role in the triggering of $\mathrm{AICD}{ }^{36,39,41}$

\section{GCH and induction of T-cell apoptosis}

$\mathrm{GCH}$ can induce apoptosis in various cells including human osteoclast and osteoblast precursors, epithelial cells, eosinophils and lymphocytes. ${ }^{34-37,42-44} \mathrm{~A}$ number of different, and in some cases cross-interacting, mechanisms are responsible for this effect (Figure 1).

Since the original observation by Wyllie, it is well known that $\mathrm{GCH}$ induce death of both rodents and human thymocytes, and of more differentiated T cells in vitro and in vivo. This effect requires dimerization of the GR and direct binding to DNA GCH response element (GRE) 2,6,45,46 and contribute to the anti-leukemia effect, to thymus atrophy and, at least in part, to the declining of T-cell number in the peripheral blood that follows $\mathrm{GCH}$ administration.

It has been shown that $\mathrm{GCH}$-induced PCD is associated with $\mathrm{Ca}^{2+}$ influx and/or mobilisation and activation of endonucleases, and is partially independent from a cytochrome-C/Apaf-1-linked pathway. ${ }^{42,43,46}$ However, recent results suggest that DEX can induce mitochondria permeability transition, which then results in cytochrome-C release and activation of PCD. ${ }^{47}$

Moreover, an increase of phosphatidylinositol-specific phospholipase C (PI-PLC) activity is required which precedes sequential acidic sphingomyelinase activation (aSMase), early ceramide production, caspases cascade activation (including caspases 3 and 6$)^{48-50}$ and gene transcription. These results are in agreement with previous observations indicating that ceramide may contribute to caspases activation. ${ }^{51}$ Interestingly enough, it has been recently reported that neutral sphingomyelinase (nSMase) activation and ceramide production also regulates IL-2 gene transcription and cell death. ${ }^{52}$

Although transcription inhibitors do not interfere with the upstream signal pathway (PI-PLC, ceramide and caspases), induction of gene transcription is necessary in order that cell death occurs and transcription inhibitors completely prevent $\mathrm{GCH}$-induced thymocytes apoptosis. ${ }^{51,53}$ This observation, indicating that protein synthesis is required after caspases activation, suggests that caspases may be necessary but not sufficient for cell death induction. In addition it could be hypothesised that caspases activation not only precedes but is also involved in the transcription regulation which then is responsible for 


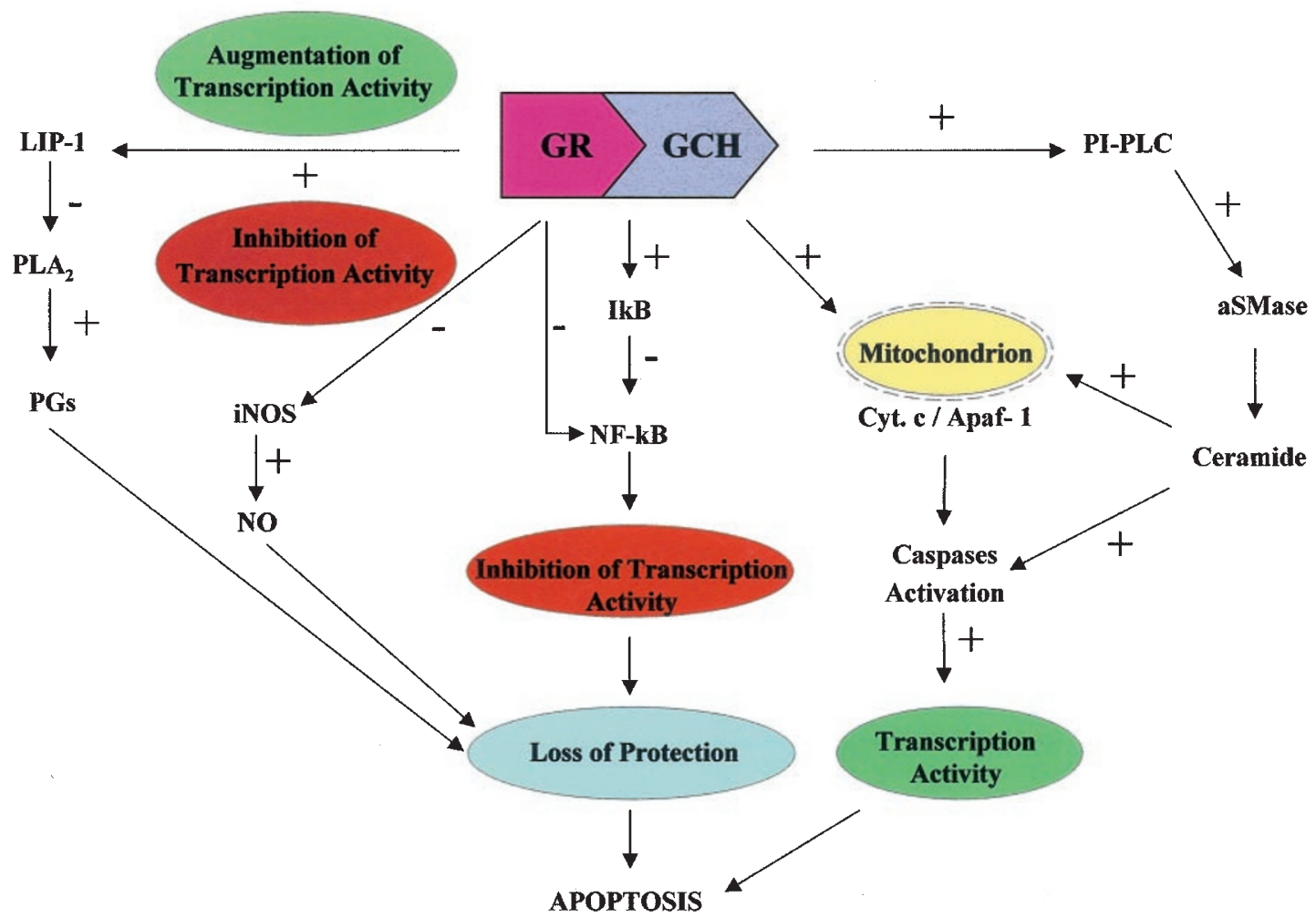

Figure 1 Possible sequential signalling events in DEX-induced apoptosis. After DEX/GR interaction a number of molecular events constitute different deathtriggering pathways. In particular, DEX-induced activation of caspases 3 and 6 has been proposed. ${ }^{48-50}$ Inhibition of NO and/or PGs production results in an apoptosis induction when either NO or PGs protect from cell death. Loss of protection can also be induced by NF- $\kappa$ B activity inhibition. Transcription activity regulation, either RNA or protein synthesis, is upstream and/or downstream in the pathways. Note that other mechanisms, which do not appear in the figure, are possible

cell death. In fact, in agreement with this hypothesis, it has recently been reported that caspase-3 can regulate the activity of NF- $\kappa \mathrm{B}$, a transcription factor involved in the regulation of apoptosis. ${ }^{54}$ Moreover, this complex signal pathway is only activated following the $\mathrm{GCH} / \mathrm{GR}$ interaction so that it is completely inhibited by GR antagonists, suggesting that non-transcription and transcription events are activated by $\mathrm{GCH} / \mathrm{GR}$ interaction and constitute a sequential transduction pathway that runs from PI-PLC activation to gene transcription, which then activates apoptosis (Figure 1). A number of DEX-induced transcripts have been described to associate with PCD in immature thymocytes. ${ }^{55}$ More recently, a cDNA has been described that codes for a $\mathrm{Ca}^{2+}$-binding protein and is a component of the $\mathrm{GCH}$-triggered cell death. ${ }^{56}$ However, the possible apoptotic role of newly activated genes remains a matter of debate and requires further studies aimed to define the specific role of each induced gene in the regulation of $\mathrm{T}$-cell survival.

Other molecular mechanisms can play a role in the $\mathrm{GCH}$ induced apoptosis. In fact, $\mathrm{GCH}$ are able to inhibit prostaglandin (PG) synthesis, through up-regulation of LIP1 and down-modulation of phospholipase $A_{2}\left(P L A_{2}\right)$ genes transcription, ${ }^{9}$ and nitric oxide (NO) generation, ${ }^{2}$ through inhibition of inducible nitric oxide synthase (iNOS) gene transcription. Moreover, both NOS and iNOS have been described in thymocytes, normal $\mathrm{T}$ lymphocytes and a number of T-cell lines, ${ }^{57-61}$ and it has been reported that both PGs and NO modulate cell survival by either inducing or inhibiting lymphocyte PCD. ${ }^{62-66} \mathrm{GCH}$, through transcription regulation, could induce apoptosis in those systems where PGs and/or NO are required for cell survival (Figure 1).

Similarly, GCH-mediated activity inhibition of the NF- $\kappa \mathrm{B}$ transcription factor, either directly or by $\mathrm{I}-\kappa \mathrm{B}$ up-regulation, ${ }^{67,68}$ can contribute to cell death regulation. In fact, it has been shown that NF- $\kappa \mathrm{B}$ acts as a survival factor in many cell systems. ${ }^{69,70} \mathrm{GCH}$-induced inhibition of $\mathrm{NF}-\kappa \mathrm{B}$ transcription activity could contribute to apoptosis induction in those cells where NF- $\kappa$ B/DNA binding is required for survival. ${ }^{68}$ All the above mentioned $\mathrm{GCH}$-activated pathways, the result of a number of different molecular events, require transcription activity regulation.

\section{GCH and inhibition of T-cell apoptosis}

$\mathrm{GCH}$ can induce a transcription-dependent inhibition of PCD in different cell types, including fibroblasts, epithelial cells and lymphocytes. ${ }^{37,38,71}$ In particular, it has been suggested that the DEX-induced inhibition of TCR-activated death is 
attributable to the transcription inhibition of the Fas/FasL complex expression. ${ }^{39}$ More recently, two DEX-induced genes, able to inhibit the Ag/TCR-activated apoptosis, have been described. In particular, it has been reported that overexpression of one of those genes, named GILZ, inhibits the activation-induced expression of Fas and FasL (see below). These observations suggest that the effect of a single agent on cell death or survival is unpredictable, when a complex of signals and stimuli interact in the same tissue, and that the $\mathrm{GCH}$-induced inhibition of apoptosis depends on transcription regulation. The $\mathrm{Ag} / \mathrm{TCR}$ interaction itself can result either in the positive (survival) or negative (apoptosis) selection of $\mathrm{T}$ cells, and other co-signals, including those delivered by coaccessory molecules $\mathrm{CK}$ and $\mathrm{GCH}$, can favour one or the other event.

In particular, in vivo administration of DEX counters the lymph nodes $\mathrm{CD}^{+}$and $\mathrm{CD}^{+} \mathrm{T}$ lymphocyte death activated by SEB administration. ${ }^{40}$ Moreover, GR lacking mice have altered thymocytes death and defective $\mathrm{T}$ cell in the periphery, indicating that $\mathrm{GCH}$ do play a role in the regulation of in vivo physiological process of T-cell death and selection. ${ }^{72}$

\section{GITR: a new receptor of the tumor necrosis factor/ nerve growth factor receptor (TNF/NGFR) family}

To study the role of glucocorticoid hormones in the regulation of lymphocyte apoptosis, we attempted the identification of genes activated by treatment with DEX in T cells. Comparing the cDNAs from untreated and DEX-treated cells, we identified some cDNAs only detectable in the treated cells. One of them, GITR (GITR, for: Glucocorticoid-Induced TNFR family-Related gene), displayed an increased expression detectable in $\mathrm{T}$ cells following DEX due to regulation at the transcription level. ${ }^{73}$ Moreover, the gene expression is also induced by stimulation of the TCR complex, suggesting that GITR could play a role in T-cell activation. GITR is characterised by three cysteine pseudorepeats and displays significant homologies with members of the TNF/NGFR family. ${ }^{73-76}$

Despite the presence of common cysteine rich motifs in the extracellular domains, molecules of the TNF/NGFR family have different cytoplasm domains. The GITR cytoplasm domain has a striking homology with the cytoplasm domains of murine and human 4-1BB, CD27 and OX40, but does not show significant homology with that of other members of the TNF/NGFR family. ${ }^{73,75,76}$ The similarity of the intracellular domain defines a new intracellular motif which could distinctivly identify a subfamily of the TNF/NGFR family, including GITR, 41BB, CD27 and OX40, from the one characterised by the death domain.

Transfection of selected hybridoma T-cell clones, that do not spontaneously express detectable GITR, confers resistance to TCR/CD3-induced apoptosis. Clones overexpressing GITR show some resistance to anti-CD3 mAbinduced apoptosis. However, modulation of GITR expression does not modify sensitivity to apoptosis stimuli different than TCR triggering such as irradiation, starvation and Fas-triggering. Moreover, in preliminary experiments a slight increase to DEX-induced apoptosis has been observed. These data suggest that GITR can modulate lymphocyte death and also that the effect, either protective or predisposing to apoptosis, is dependent on the apoptosis stimulus and/or cell activation.

The increase of GITR expression, following T-cell activation, suggests that this gene could modulate $T$ lymphocyte AICD. Thus, T-lymphocyte activation could result in the induction of expression of molecules of the TNF/NGFR family, which can either activate or inhibit apoptosis. The balance between activating and inhibiting signals may represent a complex network involved in the control of T-cell survival and immune response progression. In this respect the data on the anti-apoptosis effect of GITR should be considered with caution, since it has been previously shown that a variety of agents and stimuli (including T-cell activation via $\mathrm{Ag} / \mathrm{TCR}$ interaction) can either induce or inhibit apoptosis, depending on the experimental system adopted. ${ }^{77,78}$

These observations have implications for the evolution and function of the TNF/NGFR family, as well as for the mechanism of control of apoptosis in T-cells, and further suggest that $\mathrm{GCH}$ can activate transcription of genes able to regulate $\mathrm{T}$-cell death (either induce or inhibit it) depending from the stage of T-cell activation and/or differentiation and the concomitant presence of other stimuli.

\section{GITR and signal transduction pathway}

The homology of GITR cytoplasm domain with other members of the TNF/NGFR family members such as 41BB, CD27 and OX40, opens the problem of signal transduction. ${ }^{79-81}$ In particular, like CD27, a coaccessory molecule previously described to either induce or inhibit apoptosis, ${ }^{82,83}$ GITR can bind Siva, a pro-apoptotic protein characterised by a peculiar death-domain able to activate apoptosis. ${ }^{83}$ In fact, CD27 provides not only co-stimulatory signals able to protect lymphocytes and stimulate the immune response, but also induce cell death, and this can be explained on the base of Siva interaction. ${ }^{82,83}$ Like CD27, GITR binds Siva, so that might also induce apoptosis (Figure 2), which is in keeping with the well known capability of $\mathrm{GCH}$ to either induce or inhibit apoptosis.

\section{GILZ, a new leucine zipper family gene, regulates AICD}

We also identified a new gene overexpressed in DEX-treated cells that we named GILZ (Glucocorticoid-Induced Leucine Zipper gene). ${ }^{84}$ The protein putatively encoded by the GILZ mRNA is a leucine zipper protein of 137 aa with significant homologies with other molecules belonging to the leucinezipper family ${ }^{85-89}$, as indicated by the presence of four leucine residues at positions 76, 83, 90 and 97 and one asparagine at position 87 . Furthermore, a PAR region, rich in proline and acidic residues, is present at the $3^{\prime}$ end region. GILZ is detectable in the nucleus of transfected clones, suggesting that like other leucine zipper molecules it might be involved in transcription regulation. 

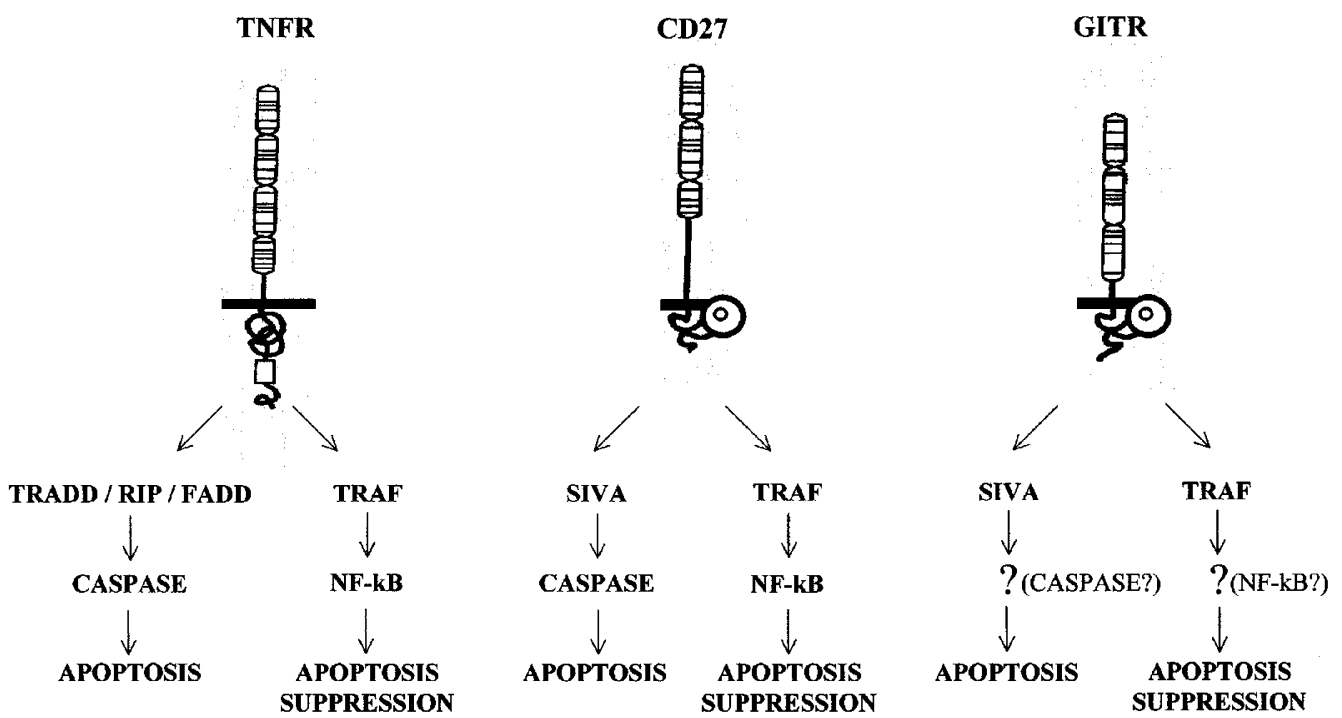

Figure 2 TNFR, CD27 and GITR can either induce or inhibit cell death through different signalling events

GILZ is expressed in normal T cells and this constitutive expression was clearly increased by treatment with DEX and inhibited by TCR-triggering in fresh thymocytes and T lymphocytes from peripheral lymphoid tissues, including spleen and lymph nodes.

We tested the possible effects of GILZ expression on Tcell apoptosis. The results obtained with transfected hybridoma T cells that do not express detectable GILZ, showed that cell clones overexpressing GILZ were variably resistant to anti-CD3 mAb-induced apoptosis when compared to control clones. On the contrary, GILZ overexpression did not counter apoptosis induced by DEX, various doses of UV irradiation, starvation or triggering by crosslinked anti-Fas mAb. These results suggest that GILZ gene can modulate apoptosis of hybridoma T-cell clones induced by treatment with antiCD3 mAb and that could contribute in part to the DEXinduced inhibition of TCR/CD3-activated apoptosis. ${ }^{36,39,72}$

It has been suggested that AICD is also dependent on Fas/FasL interaction. ${ }^{24-26}$ Thus, we performed experiments to assess whether the inhibition of apoptosis in GILZ-transfected cells could be mediated by an effect on Fas/FasL system expression. Results show that TCR complex activation by anti-CD3 mAb treatment, induced augmentation of Fas and induction of FasL expression in clones transfected by the empty vector, but did not augment Fas and FasL expression in T-cell clones overexpressing GILZ. These date indicate that GILZmediated inhibition of anti-CD3-induced apoptosis is the result, at least in part, of the inhibition of Fas and FasL mRNA expression and further confirms previous observations showing that DEX can inhibit FasL expression, thus regulating AICD. ${ }^{39-41}$ In fact, GILZ could interact either with signal(s) induced by TCR/CD3 triggering in activated lymphocyte, or directly with transcription factors such as NF-AT, NF- $\kappa$ B and Erg3, involved in the T-cell activation and regulation of Fas and FasL gene expression, acting as a transcription repressor.

\section{GILZ and regulation of cell death: role of NF- $\kappa$ B}

It has recently been reported that the NF- $\kappa \mathrm{B}$ complex, which has also been shown to either induce or protect from apoptosis, ${ }^{67,90}$ is important in the promotion of FasL gene expression. ${ }^{91,92}$ We performed experiments to test whether GILZ could modulate NF- $\kappa \mathrm{B}$ activity. Shift and competition experiments indicate that GILZ inhibits NF- $\kappa$ B DNA binding, a pre-requisite for its transcription activity and consequent regulation of cell death. Moreover, transfection experiments indicate that GILZ antagonises in vivo the NF- $\kappa$ B transcription promoting activity (Ayroldi et al, submitted for publication). These observations suggest that in some conditions, including differentiation and/or activation state and presence of co-stimulatory signals, GILZ could induce apoptosis by inhibiting the NF- $\kappa$ B activity, which fits in with the well known capability of GCH to either induce or inhibit apoptosis (Figure 3). In fact, inhibition of $\mathrm{NF}-\kappa \mathrm{B}$, while it may counter FasL expression and FasL-dependent death, could result in PCD induction when NF- $\kappa \mathrm{B}$ acts as a protective factor. ${ }^{93}$

\section{The dual effect: a common event of many apoptosis regulators}

This $\mathrm{GCH}$-induced dual effect (cell death activation and inhibition) is common to many apoptosis modulators. As an example, it has been previously shown that CD2 can either induce or counter lymphocyte apoptosis and similar results have been obtained with IL-1 and IL-2 that can inhibit DEX-or TCR-activated PCD but also predispose $T$ cells to die. ${ }^{28,29,94,95}$ In this respect, it has been reported that TNF binding to the TNFR potentially inhibits apoptosis through caspases activation, but also binds Traf-1, Traf-2, RIP and 


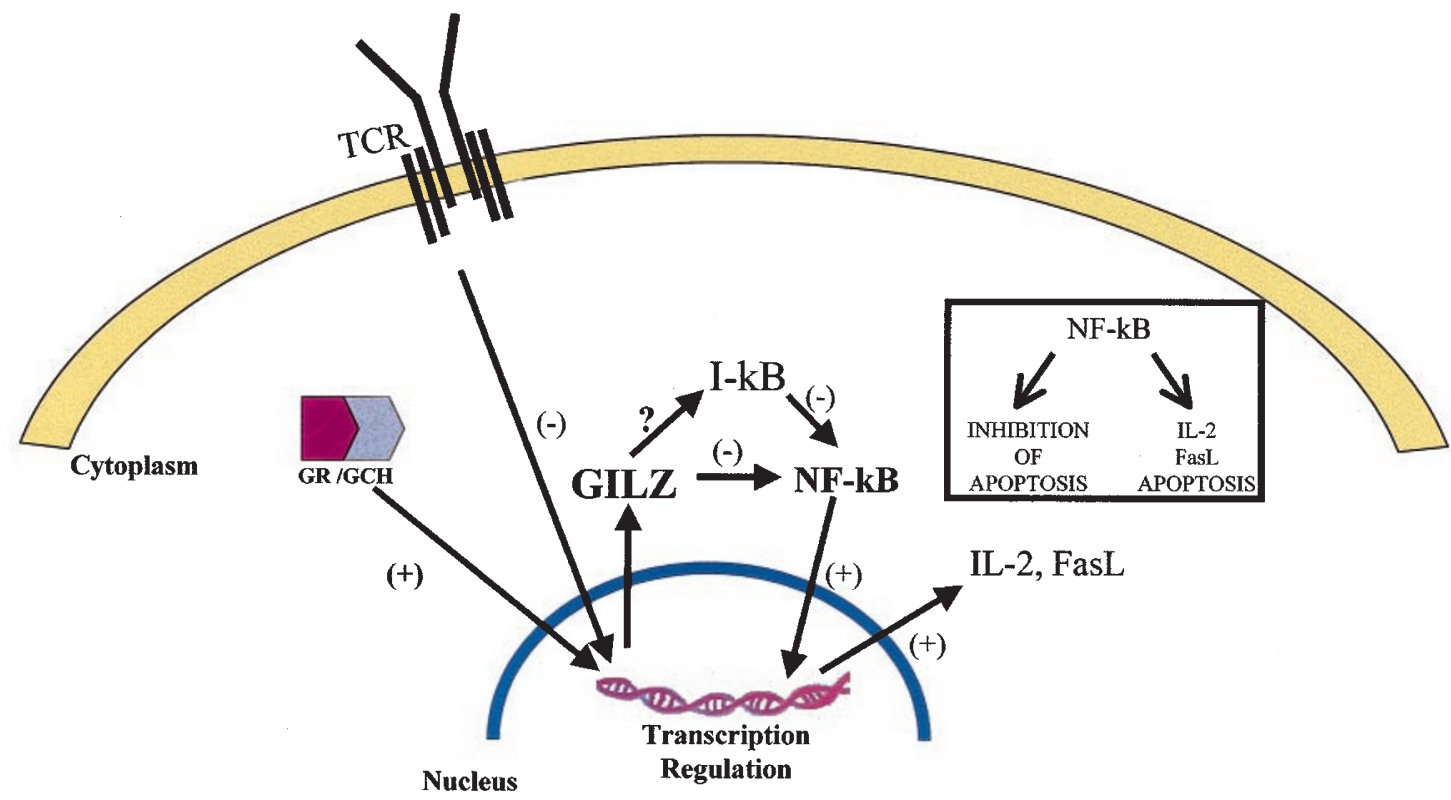

Figure 3 GILZ inhibits NF- $\kappa$ B activity, IL-2 and FasL expression

activates NF- $\kappa$ B transcription which suppresses apoptosis by an unknown mechanism. Moreover, it has been shown that TNF can inhibit death in pre-treated cells. ${ }^{96}$ Similar results have been obtained with CD27 that can either induce lymphocyte death via Siva, or protect from apoptosis via interaction with Traf-2 and NF- $\kappa$ B activation, or like 4-1BB and OX40, acting as a co-accessory molecule. ${ }^{82,83}$ Moreover, augmented expression of intracellular molecules such as heat shock protein 70 ( $\mathrm{HSP} 70)$ or $\mathrm{NF}-\kappa \mathrm{B}$ has been associated with either protection and induction of apoptosis. ${ }^{97-99}$ All these observations suggest that a number of signals and stimuli can either induce or protect from apoptosis depending on the stage of T-cell differentiation and activation and contemporary presence of other stimuli. Some of these effects also depend on transcription regulation.

\section{Conclusion}

$T$ cells are under the control of a number of stimuli which can contribute to maintain naïve cells surviving and to modulate the Ag-driven development of immune response, either by positive selection and clonal expansion or by negative selection which, together with anergy, contribute to acquire tolerance. In particular, Ag-activated negative selection, a transcription-dependent event, ${ }^{100}$ is mediated by apoptosis and is responsible for the elimination of autoreactive clones in the thymus and of the peripheral control of the magnitude of an immune response. $\mathrm{Ag} / \mathrm{TCR}$ interaction may then induce or counter apoptosis, depending on the stage of T-cell activation and the presence of other stimuli that participate T-cell selection through transcription regulation of gene expression. Studies in a number of experimental systems, including GRnegative mice, indicate that $\mathrm{GCH}$ can either activate and/or inhibit $T$ lymphocyte death. These effects suggest a role for steroids in the modulation of immune response, by either induction or inhibition of apoptosis, by complex mechanisms that also require transcription regulation of gene expression. The balance between death-inducing and survival signals will contribute to determine the survival or death and the outcome of the T-cell selection.

The knowledge of the molecular mechanisms involved in $\mathrm{GCH}$-mediated PCD modulation could further contribute to better define the therapeutic approaches aimed to obtain cytotoxic or protective effects in normal and transformed lymphocytes.

\section{Acknowledgements}

This study was supported by the Associazione Italiana Ricerca sul Cancro (AIRC), Milan, Italy. GenBank accession numbers are: GILZ: AF024519, GITR: U82534.

\section{References}

1. Cupps TR and Fauci AS (1982) Corticosteroid-mediated immunoregulation in man. Immunol. Rev. 65: 133-155

2. Barnes PJ and Adckock I (1993) Anti-inflammatory actions of steroids: molecular mechanisms. Trends Pharmacol. Sci. 14: 436-441

3. Hoffman GS (1993) Immunosuppressive therapy for autoimmune diseases. Ann. Allergy 70: 263-274

4. Wlemik PH (1996) Leukemia and myeloma. In Cancer Chemotherapy and Biological Response Modifiers, Pinedo HM, Longo DL and Chabner BA (eds), (Amsterdam, the Netherlands: Elsevier Science BV) pp. 347-375

5. Kwak LW and Longo DL (1996) Lymphomas. In Cancer Chemotherapy and Biological Response Modifiers, Pinedo HM, Longo DL and Chabner BA (eds) Amsterdam, the Netherlands: Elsevier Science BV). pp. 367-440

6. Beato M (1989) Gene regulation by steroid hormones. Cell 56: $335-344$

7. Anuradha R and Prefontaine KE (1994) Physical association and functional antagonism between the p65 subunit of transcription factor NF- $k B$ and the glucocorticoid receptor. Proc. Natl. Acad. Sci. USA 91: 752-756 
8. Re F, Muzio M, De Rossi M, Polentarutti N, Giri JC, Mantovani A and Colotta F (1994) The type II 'receptor' as a decoy target for interleukin 1 in polymorphonuclear leukocytes: characterization of induction by dexamethasone and ligand binding properties of the released decoy receptor. J. Exp. Med. 179: $739-743$

9. Di Rosa M, Calignano A, Carnuccio R, lalenti A and Sautebin L (1986) Multiple control of inflammation by glucocorticoids. Agents Actions 17: 284-289

10. Wiegers GJ and Reul JMHM (1998) Induction of cytokine receptors by glucocorticoids: functional and pathological significance. Trends Pharmacol. Sci. 19: $317-321$

11. Backstrom BT, Muller U, Hausmann B and Palmer E (1998) Positive selection through a motif in the $\alpha \beta$ T cell receptor. Science 281: 835-838

12. Raff MC (1992) Social controls on cell survival and cell death. Nature 356:397 399

13. Boise LH and Thompson CG (1996) Hierarchical control of lymphocyte survival. Science 274: $67-68$

14. Crabtree GR (1989) Contingent genetic regulatory events in T lymphocyte activation. Science 243: 355-361

15. Suda T, Okazaki T, Naito Y, Yokota T, Arai N, Ozaki S, Nakao K and Nagata S (1995) Expression of the Fas ligand in cells of T cell lineage. J. Immunol. 154 $3806-3813$

16. Green DR and Ware CF (1997) Fas-ligand: privilege and peril. Proc. Natl. Acad Sci. USA 94: $5986-5990$

17. Pinkoski MJ and Green DR (1999) Fas ligand, death gene. Cell Death Differ. 00 000-000

18. Kuo CT, Veselits ML and Leiden JM (1997) LKLF: a transcriptional regulator of single-positive T cell quiescence and survival. Science 277: 1886-1990

19. Akbar AN, Borthwick N, Salmon M, Gombert W, Bifill M, Shamsadeen N, Pilling D, Pett S, Grundy JE and Janossy G (1993a) The significance of low bcl-2 expression by CD45RO T cells in normal individual and patients with acute vira infection. The role of apoptosis in T cell memory. J. Exp. Med. 178: 427-438

20. Akbar AN, Salmon M, Savill J and Janossy G (1993) A possible role for bcl-2 in regulating T-cell memory: a 'balancing act' between cell death and survival. Immunol. Today 14: 526-532

21. Jenkinson EJ, Kingston R, Smith CA, Williams GT and Owen JJ (1989) Antigeninduced apoptosis in developing T cells: a mechanism for negative selection of the T cell receptor repertoire. Eur. J. Immunol. 19: 2175-2177

22. MacDonald HR and Lees RK (1990) Programmed death of autoreactive thymocytes. Nature 343: 642-644

23. Dent AL, Matis LA, Hooshmand F, Widacki SM, Bluestone JA and Hedrick SM (1990) Self-reactive gamma delta T cells are eliminated in the thymus. Nature 343: $714-719$

24. Ju ST, Panka DJ, Cui H, Ettiger R, el-Khatib M, Sherr DH, Stanger BZ and Marshak-rothstein A (1995) Fas(CD95)/FasL interactions required for programmed cell death after T-cell activation. Nature 373: 444-448

25. Alderson ML, Tough TW, Davis-Smith T, Braddy S, Falk B, Schooley KA, Goodwin RG, Smith CA, Ramsdell F and Lynch DH (1995) Fas ligand mediates activation-induced cell death in human T lymphocytes. J. Exp. Med. 181: 71 77

26. Dhein J, WalczakH, Baumler C, Debatin KM and KrammerPH(1995) Autocrine T-cell suicide mediate by APO-1(Fas/CD95). Nature 373: 438-441

27. Migliorati G, Nicoletti I, Pagliacci MC, D'Adamio L and Riccardi C (1993) Interleukin-4 protects double-negative and CD4 single-positive thymocytes from dexamethasone-induced apoptosis. Blood 81: 1352-1358

28. Nieto MA, Gonzalez A, Lopez Rivas A, Diaz-Espada F and Gambon F (1990) IL2 protects against anti-CD3-induced cell death in human medullary thymocytes. J. Immunol. 145: 1364-1369

29. Ayroldi E, Migliorati G, Cannarile L, Moraca R, Delfino DV and Riccardi C (1997) CD2 rescues T cell from T-cell receptor/CD3 apoptosis: a role for the Fas/FasL system. Blood 89: 3717-3726

30. Ayroldi E, Cannarile L, Migliorati G, Bartoli A, Nicoletti I and Riccardi C (1995) CD44 (Pgp-1) inhibits CD3 and dexamethasone-induced apoptosis. Blood 86: 2672-2678

31. Ayroldi E, Zollo O, Cannarile L, D'Adamio F, Grohmann U, Delfino DV and Riccardi C (1998) Interleukin-6 prevents activation-induced cell death: IL-2independent inhibition of Fas/fasL expression and cell death. Blood 92: 1 -9

32. Walker LS, McLeod JD, Boulougouris G, Patel YI, Hall ND and Sansom DM (1998) Down-regulation of CD28 via Fas (CD95): influence of CD28 on T-cell apoptosis. Immunology 94: 41-47
33. Renauld JC, Vink A, Louahed J and Van Snick J (1995) Interleukin-9 is a major anti-apoptotic factor for thymic lymphomas. Blood 85: 1300-1305

34. Wyllie AH (1980) Glucocorticoid-induced thymocyte apoptosis is associated with endogenous endonuclease activation. Nature 284: 555-558

35. Cohen JJ and Duke RC (1984) Glucocorticoid activation of a calcium dependent endonuclease in thymocyte nuclei leads to cell death. J. Immunol. 132: 38-43

36. Bansal N, Houle A and Melnykovych G (1991) Apoptosis: mode of cell death induced in T cell leukaemia lines by Dexamethasone and other agents. FASEB J. 5: $211-216$

37. Zacharchuk CM, Mercep M, Chakraborti PK, Simon Jr SS and Ashwell J (1990) Programmed T lymphocyte death. Cell activation- and steroid-induced pathways are mutually antagonistic. J. Immunol. 145: 4037-4045

38. Iwata M, Hanaoka S and Sato K (1991) Rescue of thymocytes and T cell hybridomas from glucocorticoid-induced apoptosis by stimulation via the $T$ cell receptor/CD3 complex: a possible in vitro model for positive selection of the $T$ cell repertoire. Eur. J. Immunol. 21: 643-648

39. Yang Y, Mercep M, Ware CF and Ashwell JD (1995a) Fas and activationinduced Fas ligand mediate apoptosis of $T$ cell hybridomas: inhibition of Fas ligand expression by retinoic acid and glucocorticoids. J. Exp. Med. 181:16731682

40. Ayroldi E, Cannarile L, D'Adamio F and Riccardi C (1995) Superantigeninduced peripheral T-cell deletion: the effects of chemical modification of antigen-presenting cells, interleukin-4 and glucocorticoid hormones. Immunology 84: $528-535$

41. Yang Y, Minucci S, Ozato K, Heyman RA and Ashwell JD (1995) Efficient inhibition of activation-induced Fas ligand up-regulation and T-cell apoptosis by retinoids requires occupancy of both retinoid $X$ receptors and retinoic acid receptors. J. Biol. Chem. 270: 18672-18677

42. Weinstein RS, Jilka RL, Parfitt AM and Manolagas SC (1998) Inhibition of osteoblastogenesis and promotion of apoptosis of osteoblasts and osteocytes by glucocorticoids. Potential mechanisms of their deleterious effect on bone. J. Clin. Invest. 102: 274-282

43. Meagher LC, Cousin J, Seckl JR and Haslett C (1996) Opposing effects of glucocorticoids on the rate of apoptosis in neutrophilic and eosinophilic granulocytes. J. Immunol. 156: 4422-4428

44. Migliorati G, Nicoletti I, D'Adamio F, Spreca A, Pagliacci C and Riccardi C (1994) Dexamethasone induces apoptosis in mouse natural killer cells and cytotoxic $T$ lymphocytes. Immunology 81:21-26

45. Chapman MS, Askew DJ, Kuscouglu U and Miesfeld RL (1996) Transcriptional control of steroid-regulated apoptosis in murine thymoma cells. Mol. Endocrinol. 10: 967-978

46. Green DR (1998) Apoptotic pathways: the road to ruin. Cell 94: 695-698

47. Kroemer G, Dallaporta B and Resche-Rigon M (1998) The mitochondrial death/ life regulator in apoptosis and necrosis. Annu. Rev. Physiol. 60: 619-642

48. Robertson NM, Zangrilli J, Fernandes AT, Friesen PD, Litwack G and Alnemri ES (1997) Baculovirus P35 inhibits the glucocorticoid-mediated pathway of cell death. Cancer Res. 57: 43-47

49. Miyashita T, Nagao K, Krajewski S, Salvesen GS, Reed JC, Inoue T and Yamada M (1998) Investigation of glucocorticoid-induced apoptotic pathway: processing of caspase-6 but not caspase-3. Cell Death Differ. 5: 1034-1041

50. Huang S-TJ and Cidlowski JA (1999) Glucocorticoids inhibit serum depletioninduced apoptosis in T lymphocytes expressing Bcl-2. FASEB J. 13: 467-476

51. Kolesnik RN and Kronke M (1998) Regulation of ceramide production and apoptosis. Annu. Rev. Physiol. 60: 643-665

52. Tonnetti L, Veri MC, Bonvini E and D'Adamio L (1999) A role for neutral sphingomyelinase-mediated ceramide production in $T$ cell receptor-mediated apoptosis and mitogen-activated protein kinase-mediated signal transduction. J. Exp. Med. 189: 1581-1589

53. Cifone MG, Migliorati G, Parroni R, Marchetti C, Millimaggi D, Santoni A and Riccardi C (1999) Dexamethasone-induced thymocyte-apoptosis: apoptotic signal involves the sequential activation of phosphoinositide-specific phospholipase $\mathrm{C}$, acidic sphingomyelinase and caspases. Blood 93: 2282 2296

54. Reuther JY, Baldwin Jr AS (1999) Apoptosis promotes a caspase-induced amino-terminal truncation of IkappaBalpha that functions as a stable inhibitor of NF-kappaB. J. Biol. Chem. 274: 20664-20070

55. Owens GP, Hahn WE and Cohen JJ (1991) Identification of mRNAs associated with programmed cell death in immature thymocytes. Mol. Cell. Biol. 11:41774188 
56. Vito $P$, Lacanà $E$ and $D$ 'Adamio $L(1996)$ Interfering with apoptosis: $\mathrm{Ca}^{2+}$. binding protein ALG-2 and Alzheimer's disease gene ALG-3. Science 271: $521-525$

57. Yamada T, Murayama T and Nomura Y (1998) Enhancement of expression of inducible NO synthase and inhibition of DNA synthesis in rat thymocytes by in vivo hydrocortisone treatment. J. Neuroimmunol. 81: 14-9

58. Cruz MT, Carmo A, Carvalho AP and Lopes MC (1998) Calcium-dependent nitric oxide synthase activity in rat thymocytes. Biochem. Biophys. Res. Commun. 248: 98-103

59. Esaki T, Hayashi T, Asai Y, Kumar TN, Kano H, Muto E and Iguchi A (1997) Expression of inducible nitric oxide synthase in $\mathrm{T}$ lymphocytes and macrophages in vessels with advanced atherosclerosis. Heart Vessels 12: $89-92$

60. Sciorati C, Rovere P, Ferrarini M, Heltai S, Manfredi AA and Clementi E (1997) Autocrine nitric oxide modulates CD95-induced apoptosis in gammadelta $T$ lymphocytes. J. Biol. Chem. 272: 23211-23215

61. Mannick JB, Miao XQ and Stamler JS (1997) Nitric oxide inhibits Fas-induced apoptosis. J. Biol. Chem. 272: 24125-24128

62. McConkey DJ, Orrenius S and Jondal M (1990) Agents that elevate cAMP stimulate DNA fragmentation in thymocytes. J. Immunol. 145: 1227-1230

63. Suzuki K, Tadakuma T and Kizaki H (1991) Modulation of thymocyte apoptosis by isopreterenol and prostaglandin E2. Cell. Immunol. 134: 235-240

64. Goetzl EJ, An S and Zeng L (1995) Specific suppression by prostaglandin E2 of activation-induced apoptosis of human CD4+CD8+ T lymphoblasts. J. Immunol. 154: 1041-1047

65. Fehsel K, Kroncke KD, Meyer KL, Huber H, Wahn V and Kolb-bachofen V (1995) Nitric oxide induces apoptosis in mouse thymocytes. J. Immunol. 155: 2858-2865

66. Genaro AM, Hortelano S, Alvarez A, Martinez-AC and Boscà L (1995) Splenic B lymphocyte programmed cell death is prevented by nitric oxide release through mechanisms involving sustained Bcl-2 levels. J. Clin. Invest. 95: 1884-1890

67. De Bosscher K, Schimtz ML, Vanden Berghe W, Plaisance S, Fiers W and Haegeman G (1997) Glucocorticoid-mediated repression of nuclear factorkappaB-dependent transcription involves direct interference with transactivation. Proc. Natl. Acad. Sci. USA 94: 13504-13509

68. Auphan N, DiDonato JA, Rosette C, Helmberg A and Karin M (1995) Immunosuppression by glucocorticoids: inhibition of NF- $\kappa$ B activity through induction of $I_{\kappa} B$ synthesis. Science $270: 286-289$

69. Wang CY, Mayo MW and Baldwin AS (1996) TNF- and cancer therapy-induced apoptosis: potentiation by inhibition of NF- $\kappa$ B. Science 274: 784-787

70. Beg AA, Sha WC, Bronson RT, Ghosh S and Baltimore D (1995) Embryonic lethality and liver degeneration in mice lacking the RelA component of NF- $k B$. Nature 376: 167-170

71. Pagliacci MC, Migliorati G, Smacchia M, Grignani F, Riccardi $C$ and Nicoletti (1993) Cellular stress and glucocorticoid hormones protect L929 mouse fibroblasts from tumor necrosis factor alpha cytotoxicity. J. Endocrinol. Invest. 16: $591-599$

72. King LB, Bacchio MS, Dixon K, Hunziker R, Margulies DH and Ashwell JD (1995) A targeted Glucocorticoid receptor antisense transgene increases thymocyte development. Immunity 3: 647-656

73. Nocentini G, Giunchi L, Ronchetti S, Krausz LT, Bartoli A, Moraca R, Migliorati G and Riccardi C (1997) A new member of the tumor necrosis factor/nerve growth factor receptor family inhibits $T$ cell receptor-induced apoptosis. Proc. Natl. Acad. Sci. USA 94: 6216-6221

74. Gruss HJ and Dower SK (1995) Tumor necrosis factor ligand superfamily: involvement in the pathology of malignant lymphomas. Blood 85: 3378-3804

75. Kwon BS and Wessman SM (1989) cDNA sequences of two inducible T-cell genes. Proc. Natl. Acad. Sci. USA 86: 1963-1967

76. Gravenstein LA, Blom B, Nolten LA, de Vries E, van der Horst G, Ossendorp F, Borst J and Loenen WAM (1993) Cloning and expression of murine CD27: comparison with 4-1BB, another lymphocyte-specific member of the nerve growth factor receptor family. Eur. J. Immunol. 23: 943-950

77. Golstein P, Ojcius DM and Young JD (1991) Cell death mechanisms and the immune system. Immunol. Rev. 121: 26-65

78. Hale AJ, Smith CA, Sutherland LC, Stoneman VE, Longthorne VL, Culhane AC and Williams GT (1996) Apoptosis: molecular regulation of cell death. Eur. J. Biochem. 236: 1-26

79. Jang IK, Lee ZH, Kim Y, Kim SH and Know BS (1998) Human 4-1BB (Cd137) signals are mediated by TRAF2 and activate nuclear factor-kB. Biochem. Biophys. Res. Comm. 242: 613-620
80. Arch RH and Thompson CB (1998) 4-1BB and Ox40 are members of a tumor necrosis factor (TNF)-nerve growth factor receptor subfamily that bind TNF receptor-associated factors and activate nuclear factor kB. Mol. Cell. Biol. 18: $558-565$

81. Kawamata S, Hori T, Imura T, Takaori-kondo A and Uchiyama T (1998) Activation of $\mathrm{OX} 40$ signal transduction pathways leads to tumor necrosis factor receptor-associated factor (TRAF)2-and TRAF5-mediated NFkB activation. J. Biol. Chem. 273: 5808-5814

82. Prasad KVS, Ao Z, Yoon Y, Wu MX, Rizk M and Jacquot S (1997) CD27, a member of the tumor necrosis factor receptor family, induces apoptosis and binds to Siva, a proapoptotic protein. Proc. Natl. Acad. Sci. USA 94: 63466351

83. Gravenstein LA, Amsen D, Boes M, Calvo CR, Krusbeek AM and Borst J (1998) The TNF receptor family member CD27 signals to Jun N-terminal kinase via Traf-2. Eur. J. Immunol. 28: 2320-2330

84. D'Adamio F, Zollo O, Moraca R, Ayroldi E, Bruscoli S, Bartoli A, Cannarile L, Migliorati $G$ and Riccardi C (1997) A new Dexamethasone-induced gene of the leucine zipper family protects $T$ lymphocytes from TCR/CD3-activated cell death. Immunity 7: 803-812

85. Hope IA and Struhl K (1987) GCN4, a eukaryotic transcriptional activator protein, binds as a dimer to target DNA. EMBO J. 6: 2781-2784

86. Lamph WW, Wamsley P, Sassone-Corsi P and Verma IM (1988) Induction of proto-oncogene JUN/AP-1 by serum and TPA. Nature 334: 629-631

87. Yamamoto KK, Gonzales GA, Biggs III WH and Montiminy MR (1988) Phosphorylation-induced binding and transcriptional efficiency of nuclear factor CREB. Nature 334: 494-498

88. Nicholas SF, Borrelli E and Sassone-Corsi P (1991) CREM gene: use of alternative DNA-binding domains generate multiple antagonists of CAMPinduced transcription. Cell 64: 739-749

89. Shibanuma M, Kuroki T and Nose K (1992) Isolation of a gene encoding a putative leucine zipper structure that is induced by transforming growth factor beta 1 and other growth factor. J. Biol. Chem. 267: 10219-10224

90. Grimm S, Bauer MKA, Baeuerle PA and Schulze-Osthoff K (1996) Bcl-2 downregulates the activity of transcription factor NF-kB induced upon apoptosis. J. Cell Biol. 134: 13-23

91. Matsui K, Fine A, Zhu B, Marshak-Rothstein A and Ju S-T (1998) Identification of two NF-kB sites in mouse CD95 ligand (Fas ligand) promoter: functional analysis in T cell hybridoma. J. Immunol. 161: 3469-3473

92. Mittelstadt PR and Ashwell JD (1998) Cyclosporin A-sensitive transcription factor Egr-3 regulates Fas ligand expression. Mol. Cell. Biol. 18: 3744-3751

93. Ramdas J and Harmon JM (1998) Glucocorticoid-Induced Apoptosis and Regulation of NF-kB Activity in Human Leukemic T Cells. Endocrinology 139: 3813-3821

94. Deas O, Dumont C, MacFarlane M, Rouleau M, Hebib C, Harper F, Hirsch F Charpentier B, Cohen G and Senik A (1998) Caspase-independent cell death induced by anti-CD2 or staurosporine in activated human peripheral $T$ lymphocytes. J. Immunol. 161: 3375-3383

95. Lenardo MJ (1991) Interleukin-2 programs mouse alpha beta T lymphocytes for apoptosis. Nature 353: 858-861

96. Belizzario JE and Dinarello CA (1991) Interleukin-1, interleukin-6, tumor necrosis factor and transforming growth factor $\beta$ increase cell resistance to tumor necrosis factor cytotoxicity by growth arrest in the G1 phase of the cell cycle. Cancer Res. 51: 2379-2385

97. Migliorati G, Nicoletti I, Crocicchio F, Pagliacci C, D'Adamio F and Riccardi C (1992) Heat Shock induces apoptosis in mouse thymocytes and protects them from glucocorticoid-induced cell death. Cell. Immunol. 143: 348-356

98. Urayama S, Musch MW, RetskyJ, Madonna MB, Straus D and Chang EB (1998) Dexamethasone protection of rat intestinal epithelial cells against oxidant injury is mediated by induction of heat shock protein 72 . J. Clin. Invest. 102: 18601865

99. Wang CY, Mayo MW, Korneluk RG, Goeddel DV and Baldwin Jr AS (1998) NF$\kappa \mathrm{B}$ antiapoptosis: induction of TRAF1 and TRAF2 and c-IAP1 and c-IAP2 to suppress caspase-8 activation. Science 281: $1680-1683$

100. D'Adamio L, Awad KM and Reinherz EL (1993) Thymic and peripheral apoptosis of antigen-specific $\mathrm{T}$ cells might cooperate in establishing self tolerance. Eur. J. Immunol. 23: 747-753 